\title{
A 2-year audit of the Emergency Airway Service in a Singaporean Regional Hospital
}

\section{Quek KH, Ong ASC, Ong CS \\ Changi General Hospital, Department of Anaesthesiology \& Surgical Intensive Care, Singapore}

\section{Background and Goals:}

Compared to in-theatre intubation, emergency out-of-theatre endotracheal intubation (EEI) is associated with higher rates of failed intubation and hypoxia. In 2011, an Emergency Airway Service (EAS) was set up to manage airway emergencies outside OT. The team comprises of an anaesthetist, a trainee and a nurse with specialised equipment readily available in a runaway trolley. We describe the characteristics and outcomes of EAS activation in our hospital.

\section{Materials and Methods:}

Following institutional review board approval, we conducted a 2-year retrospective audit of EAS activations (April 2014 to April 2016). EAS forms and electronic records were reviewed. There were 135 activations, of which 90 with record forms were analysed.

\section{Results and Discussion:}

Activations originated mainly from General Ward (37\%), A\&E (19\%), Medical ICU (19\%) and High Dependency Units (18\%). Reasons for intubation included respiratory $(58 \%)$, cardiac (16\%), airway (14\%) and neurological (8\%). Median patient age was 62 years (range 18-86).

Patient characteristics and co-morbidities (number (\%))

\begin{tabular}{l|c}
\hline Patient Characteristics & $\mathbf{N}=90(\%)$ \\
\hline Male & $52(58 \%)$ \\
\hline Female & $38(42 \%)$ \\
\hline Diabetes & $46(51 \%)$ \\
\hline Obesity & $17(19 \%)$ \\
\hline Radiotherapy to Neck & $12(13 \%)$ \\
\hline Obstructive Sleep Apnoea & $8(9 \%)$ \\
\hline Primary C-Spine Pathology & $5(6 \%)$ \\
\hline Intra-oral Lesion & $4(4 \%)$
\end{tabular}

Intubation was attempted in $84(93.3 \%)$ cases by the EAS team. $83(99 \%)$ cases were intubated successfully while 1 (1\%) required open tracheostomy. Mask ventilation and intubation were deemed difficult in $29(35 \%)$ and 33 (39\%) cases respectively.

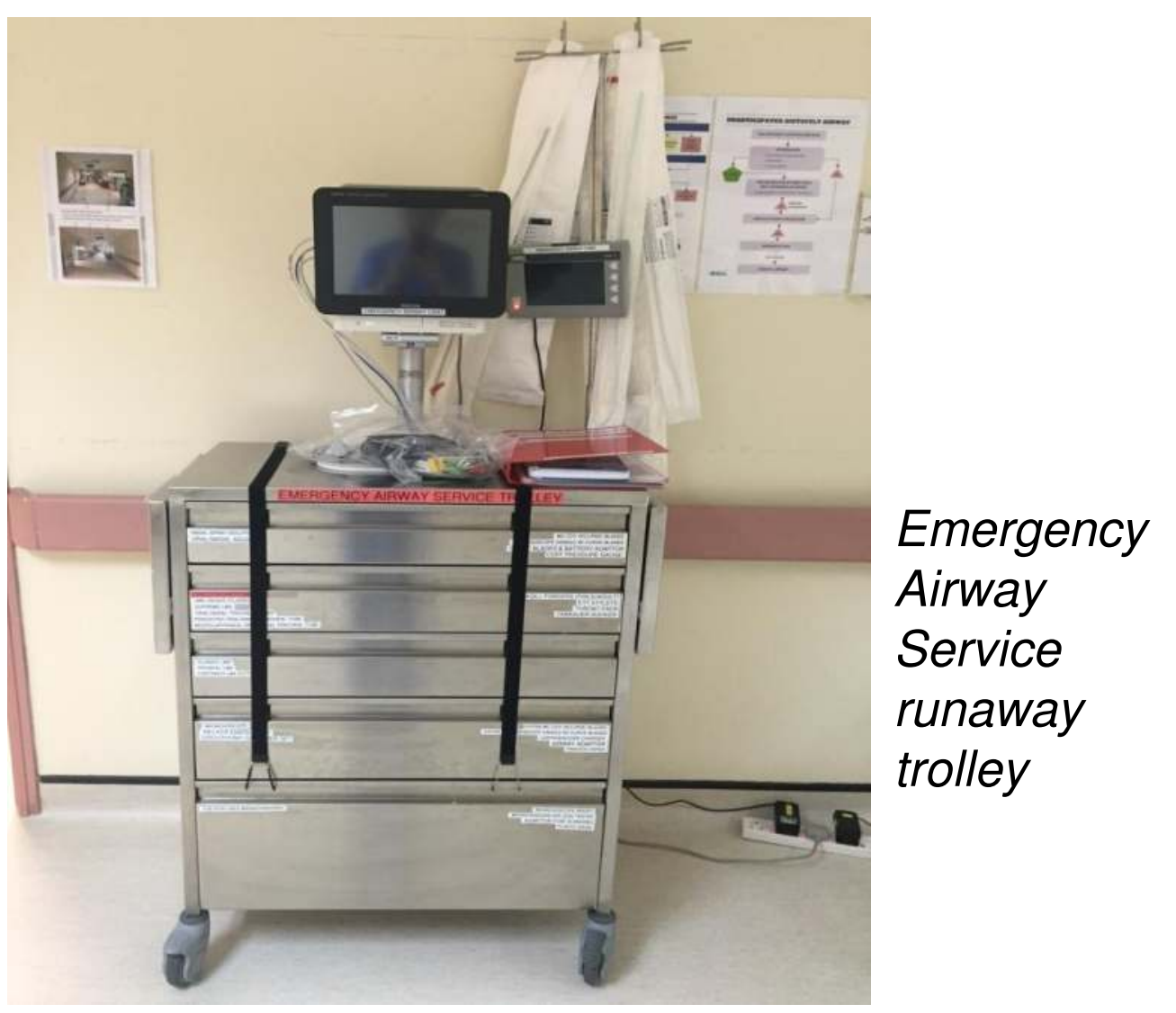

Difficulties were attributed to anatomical (53\%), pathological (28\%) and operator (19\%) reasons. Techniques used included videolaryngoscopy (73\%), direct laryngoscopy (23\%), fibreoptic bronchoscopy (3\%), and tracheostomy (1\%). Capnometry / capnography was used in $53(63 \%)$ cases to confirm endotracheal intubation. Allcause 30 -day mortality was $68 \%$ in patients who required EAS activation during their hospital stay.

We reported a higher incidence of difficult intubation compared to earlier studies, likely because the EAS was activated only when the primary team had failed intubation or anticipated difficulty. We suggest the videolaryngoscope as the first-choice device during EEI as there is good evidence that it improves glottic view and first-pass success rate. Also, we encourage our EAS team to use capnography to confirm correct tube placement, in accordance with recommendations from the National Audit Project 4.

\section{Conclusion:}

Our EAS has been successful in managing airway emergencies and EEI outside the operating theatre. We recommend that others involved in this procedure to similarly audit their practice as part of a quality improvement process.

\section{Acknowledgements:}

The authors would like to thank the Department of Anaesthesiology, CGH for permitting the use of the EAS database, and Drs $M N g$ and R Chandran for designing the original EAS audit form.

\section{References}

1. Phillips $L$ et al. Prospective observational study of emergent endotracheal intubation practice in the intensive care unit and emergency department of an Australian regional tertiary hospital. Emerg. Med. Australas. 2014; 26: 368-375.

2. Cook TM et al. Major complications of airway management in the UK: results of the Fourth National Audit Project of the Royal College of Anaesthetists and the Difficult Airway Society. Br J Anaesth. 2011 May;106(5):617-31. 